Ensino, Saúde e Ambiente -V5 (2), pp. 25.32, ago. 2012

\title{
O JORNAL IMPRESSO E A QUESTÃO AMBIENTAL- UMA PERSPECTIVA BASEDA NA TEORIA DE VYGOTSKY
}

\section{THE PRINTED JOURNAL AND THE ENVIRONMENTAL ISSUE - A PERSPECTIVE BASED ON VYGOTSKY'S THEORY}

\author{
Adriana Bedim ${ }^{1}$ e Luiza Oliveira ${ }^{2}$ \\ ${ }^{1}$ Mestrado Profissional em Ensino de Ciências da Saúde e do Ambiente/UNIPLI e Escola Municipal \\ Coronel Eliseu, adriana.bedim@yahoo.com \\ ${ }^{2}$ Universidade Severino Sombra e Instituto Superior de Educação do Estado do Rio de Janeiro, \\ luiza.oliveira@gmail.com
}

\begin{abstract}
RESUMO
Este artigo tem por objetivo discutir a relação entre a mídia impressa e a construção de conhecimento acerca da Questão Ambiental. Trata-se, portanto, de um artigo teórico, que é parte de uma pesquisa mais ampla, que analisa os conceitos de mídia impressa, de letramento e de educação ambiental. O aporte teórico é a teoria de Vygotsky. A ideia é pensar a relação entre a mídia e a educação para além das abordagens ingênuas, que reduzem a mídia a mero instrumento de entretenimento em sala de aula e para além das abordagens crítico-reprodutivistas, para as quais a mídia e a escola apenas instituem a reprodução da ordem social.
\end{abstract}

Palavras-chave: Mídia Impressa; Educação Ambiental; Vygotsky

\begin{abstract}
This article aims to discuss the print media and the construction of knowledge about environmental issues. It is thus a theoretical article, which is part of a search, which looks at the concepts of print media, literacy and environmental education. The theoretical contribution is Vygotsky's theory. The Idea is to think about the media and education in addition to the naive approaches that reduce the media to mere entertainment instrument in the class and beyond critical approaches-reprodutivistas, for which the media and the school only set out the reproduction of social order.
\end{abstract}

Key words: Print Media; Environmental Education; Vygotsky

\section{INTRODUÇÃO}

A mídia constituiu-se como uma instituição emblemática da sociedade moderna, tornando-se um recurso de informação e lazer para diversas classes sociais e para pessoas de diferentes faixas etárias. Mas, para além desta fala, podemos construir uma discussão acerca do lugar dos meios de comunicação na produção do conhecimento. Para muitos, autores de uma vertente crítico-reprodutivista, a mídia, é uma das grandes formas de produção e manutenção do discurso do modelo representativo da sociedade 
moderna capitalista, pois institui o consumo como verdade (BOURDIEU, 1997). Para outros (CERTEAU, 1994), a mídia institui-se como lugar de reprodução da ordem, mas, ao mesmo tempo, no mesmo ato, como possibilidade de transformação social.

Estamos construindo a discussão teórica que dará origem ao aporte teórico de uma pesquisa mais ampla, que pretende analisar a relação entre uma forma midiática e a educação ambiental, a partir do objetivo que é analisar a interseção da linguagem jornalística com as práticas escolares na construção de conhecimento sobre questões ambientais. Para tanto, este artigo traz uma discussão acerca do conceito de sujeito, de linguagem e de aprendizagem na teoria de Vygotsky (2001; 1994; 1972), bem como conceitos de Educação Ambiental Conservadora e Educação Ambiental Crítica, a partir dos textos de Guimarães (2006;)

Vygotsky (2001) apresenta um conceito de sujeito que é diferente do conceito de o sujeito epistêmico instituído a partir das ideias cartesianas da modernidade. $\mathrm{O}$ autor afirma que o sujeito não se organiza internamente e nem é apenas um simples fenômeno dos estímulos do ambiente, expondo, assim, um sujeito que é produzido nas relações sociais, na relação com o outro, relação instituída pela Linguagem. Vygotsky propõe a construção do sujeito diante das práticas sociais, afirma que o sujeito se constitui nas relações sociais, sendo por elas constituído e as constituindo no mesmo ato.

Esta concepção de sujeito é fundamental para pensarmos a constituição do sujeito diante da mídia: o sujeito não é apenas condicionado pelos meios de comunicação ou interage com eles de forma neutra, mas, sim, constitui-se na linguagem midiática, sendo produzido por ela e também a afetando.

Fazendo um recorte, a proposta deste estudo teórico é discutir um lugar diferente para o uso da linguagem midiática nos espaços escolares. Nas escolas é visível o apelo e a relação prazerosa que alunos e professores estabelecem com os meios de comunicação. Isto se dá, por que

\footnotetext{
A mídia invade nosso cotidiano. A criança e o adolescente de hoje não conheceram o mundo de outra maneira - nasceram imersos no mundo com telefone, fax, computadores, televisão, etc. TVs ligadas à maior parte do tempo, assistidas por qualquer faixa etária, acabam por assumir um papel significativo na construção de valores culturais. (CAMPOS e SOUZA, 2003, p. 14)
}

Entretanto, é preciso repensar o vínculo entre educação e mídia para além dos discursos que priorizam a mídia como entretenimento, podemos repensá-la como espaço de criação do sujeito, já que Vygotsky afirma que o sujeito se constitui nas relações sociais, sendo por elas constituído e as constituindo no mesmo ato. 
Atualmente uma das questões que mais é associada à utilização da mídia no espaço escolar é a Educação Ambiental, haja vista ser um dos temas transversais da educação brasileira e mais do que isso, haja vista o fato de que "há um reconhecimento generalizado no mundo sobre a seriedade dos problemas ambientais que nos afetam na atualidade" (GUIMARÃES, 2006, p. 15).

Entretanto, apenas o reconhecimento da denominada crise ambiental e seu alarde nos diversos espaços institucional, tais como mídia e escola, não é suficiente para promover uma educação ambiental crítica, ou seja, uma educação ambiental voltada para a transformação sociambiental (GUIMARÃES, 2006).

Assim, torna-se relevante pensar como essa relação instituinte do sujeito na linguagem midiática vem sendo perpassada pela Questão Ambiental, melhor dizendo, pela apropriação que a mídia faz da Questão Ambiental: como o sujeito é afetado, produzido e como ele se institui diante disso, e, ainda, como essa apropriação vem sendo produzida no espaço escolar.

\section{DESENVOLVIMENTO}

O conceito de mediação é fundamental para entendermos os conceitos de Sujeito e de Aprendizagem na teoria de Vygotsky (1994), pois segundo o autor, é através desse processo - mediação - que os processos psicológicos complexos, característicos do homem, são formados. A mediação significa que há a intervenção do Outro mais experiente no sistema de representação da realidade compartilhado, isso acontece porque é esse Outro que atribui significados à realidade na qual estamos inseridos, assim aqueles que são menos experientes poderão internalizar os modos de funcionamento psicológico de seu grupo cultural. Tal processo é denominado por Vygotsky de sociogênese.

Quando aquele que é menos experiente internaliza os modos de funcionamento, a intermediação do Outro não é mais essencial. Este é o plano da microgênese.

O plano da microgênese traz mais complexidade traz maior complexidade à questão da gênese do psiquismo. Ex: capacidade de a criança se alimentar sozinha. Em cada situação de interação com o mundo externo, o indivíduo encontra-se em um determinado momento de sua trajetória particular, trazendo consigo certas possibilidades de interpretação e re-significação do material que obtém dessa fonte externa. (OLIVEIRA, 1996, pp. 67-74). 
Esta abordagem rompe com o modelo da Modernidade, pois não expõe um sujeito existente nele mesmo ou um sujeito moldado pelo ambiente, mas o curso de desenvolvimento do sujeito só se constitui na sua inserção no mundo da cultura.

(...) a ação individual, com base na singularidade dos processos de desenvolvimento de cada sujeito, consiste em constante recriação da cultura e negociação interpessoal. Se assim não fosse, teríamos culturas sem história e geração de indivíduos idênticos em cada grupo cultural.. O sujeito, portanto, se faz como ser diferenciado do outro singular, mas constituído socialmente. (OLIVEIRA, 1996, pp. 67-74)

Vygotsky apresenta a possibilidade de pensarmos um espaço de criação na relação do sujeito com o meio. O sujeito é tal como uma obra de arte, a obra de arte, segundo Vygotsky, é um processo criativo, mas que é contextualizado em um processo histórico, sendo resultado de suas condições de possibilidade: contexto histórico, político e social de uma época. Porém, há sempre a produção do novo, o que Vygotsky chama de reelaboração criadora do antigo com o novo. É dessa forma que podemos trabalhar com a mídia em sala de aula, com a finalidade de construir conhecimento a partir da relação entre o singular e o coletivo, em uma relação entre microgênese e sociogênese.

Os conceitos de Sujeito e de Aprendizagem de Vygotsky nos aproximam de uma abordagem da denominada Educação Ambiental crítica, pois essa pretende promover formas de produzir ações que levem o sujeito a se constituir diante da Questão Ambiental, pois

Para muito de nós, a realidade concreta de uma certa área se reduz a um conjunto de dados materiais ou de fatos cuja existência ou não, de nosso ponto de vista, importa constatar. Para mim, a realidade concreta é algo mais que fatos ou dados tomados mais ou menos em si mesmos. Ela é todos esses fatos e todos esses dados e mais a percepção que deles esteja tendo a população neles envolvida (FREIRE, 1986, p. 35).

A intervenção do Outro pode e deve ser intencional, principalmente nos espaços formais de ensino, tal como a escola. Aprendizagem, para Vygotsky, promove desenvolvimento do pensamento. Assim, a aprendizagem formal tem destaque em sua teoria e os procedimentos regulares, como o uso das metodologias de ensino, que fazem parte do cenário da escola, são importantes. (VYGOTSKY, 1994). Assim, é importante discutir as metodologias em sala de aula, aqui optamos pela análise do uso da mídia na interface com a Questão Ambiental.

A Educação Ambiental Crítica deve ser entendida como um "processo de formação social orientado para desenvolvimento de uma consciência crítica sobre a 
problemática ambiental”, devemos aproximá-la da realidade concreta dos sujeitos, buscando, assim, a relação entre os processos históricos, políticos, sociais e econômicos que constituem o vínculo entre o ambiente natural e construído (REIGOTA, 1995).

o estabelecimento de relações simplistas e lineares com a problemática socioambiental e a proposição de práticas pouco inovadoras, caracterizaram-se como indicativos de baixa associação entre reflexão e ação, teoria e prática, numa perspectiva pouco crítica, não referenciada por um pensamento complexo. Tais fatos aqui constatados e também observados em outras propostas formativas, indicam limites deste processo modular e disciplinar influenciada pelos "paradigmas de disjunção" que ainda são hegemônicos nas concepções de cursos de formação na área educacional (GUIMARÃES E VASCONCELLOS, 2006, p. 150).

A proposta de aproximação com a mídia é por que Atualmente a mídia vem intensificando o debate sobre as questões ambientais através de matérias, documentários e notícias, que apresentam tema tais como aquecimento global, derretimento de geleiras, extinção de espécies animais, camada de ozônio entre outros fatos. Na mídia impressa, alguns periódicos apresentam cadernos temáticos sobre a Questão Ambiental.

Entretanto, percebemos que a mídia geralmente não trata dos assuntos ambientais sob o viés crítico. Podemos identificar alguns motivos: o distanciamento que há entre a linguagem jornalística e a linguagem científica. Segundo Oliveira (OLIVEIRA ET AL, 2007, p.3) os temas científicos, na maioria das vezes, são explorados pela mídia de forma sensacionalista.

\begin{abstract}
A escolha de temas científicos se dá porque o tratamento dado a esses pela mídia é geralmente superficial, devido a duas questões: má formação dos jornalistas diante dos conteúdos da Ciência e mistificação do papel e da produção da Ciência, o que faz com que o conhecimento gerado seja apresentado de forma espetacular e inacessível. Isto vai de encontro ao que atualmente se espera da mídia diante da Ciência, que é a realização de divulgação de conhecimento visando à aproximação do público dos conteúdos científicos, numa perspectiva de que a mídia possa se constituir como um espaço nãoformal de ensino de ciências.
\end{abstract}

Diante dessa situação, os jornalistas atendendo a demanda de rapidez na informação e da necessidade de estar à frente da concorrência com a divulgação de notícias originais, o chamado "furo de reportagem", acabam produzindo informações equivocadas, distantes da abordagem crítica da Questão Ambiental. 
Os meios de comunicação divulgam notícias descontextualizadas, tornado-as incompreensíveis para o leitor, dificultando o conhecimento crítico. Isto porque, o texto jornalístico tem uma ênfase funcionalista, construindo um discurso utilitarista acerca da Questão Ambiental. (OLIVEIRA ET AL, 2010)

A relação entre a mídia e a Questão Ambiental, não é simples, ainda mais no espaço escolar, onde não é interessante usar a mídia para divulgar conteúdos alarmantes acerca da denominada 'crise ambiental', mas, sobretudo, é importante procurar formas de interseção entre essas linguagens a fim de promover a conscientização.

A mídia impressa, o jornal, foi escolhida neste artigo, pois pode aproximar o leitor das normas da língua escrita. A apropriação da língua escrita não indica apenas a expressão de uma forma de pensamento bem elaborado, mas é, sobretudo, possibilidade de desenvolver modos mais sofisticados, abstratos de pensar.

\begin{abstract}
O domínio desse sistema complexo de signos fornece novo instrumento de pensamento (na medida em que aumenta a capacidade de memória, registro de informações etc.), propicia diferentes formas de organizar a ação e permite outro tipo de acesso ao patrimônio da cultura humana (que se encontra registrado nos livros e em outros portadores de textos). Enfim, promove modos diferentes e ainda mais abstratos de pensar, de se relacionar com as pessoas e com o conhecimento (REGO, 2000, p. 68)
\end{abstract}

A criança percebe e vivencia o uso da língua no cotidiano, mas na escola ela passa a entender que aquilo que falamos pode ser escrito e vice-versa. Portanto, os primeiros anos escolares são decisivos para tornar uma pessoa leitora, para criar o hábito da leitura, para despertar o interesse e a curiosidade pelo material impresso. Isto é às vezes muito difícil, pois este caminho para levar uma pessoa a se interessar pela leitura passa por muitos obstáculos que vão desde ter material impresso para aproximálos até a valorização familiar do educando pela aquisição da leitura e escrita.

A escola vem utilizando a mídia apenas como recurso auxiliar, facilitando o acesso às informações que fazem parte do nosso cotidiano, tornando possível o diálogo entre os conteúdos curriculares e os temas da atualidade mundial.

Neste sentido, o uso do jornal impresso cumpre este papel, pois traz para a sala de aula, fatos e assuntos da atualidade, o uso de diferentes linguagens textuais entre outros.

Percebe-se que a defesa do uso do jornal na educação escolar extrapola a preocupação de perpetuar o hábito puro e simples de ler jornais. Entende-se que sua utilização representa um compromisso político com a formação continua do aluno-leitor. (TREVISANI e OUTROS, 1998, p.18) 
Segundo Trevisani e Outros (1998), o uso do jornal, como recurso de ensino, ainda não é usado de modo rotineiro nas escolas, e isto, não é uma característica só brasileira. Ainda, segundo a autora, nos Estados Unidos o uso do jornal foi recomendado desde 1932 e sua sistematização prática só ocorreu em 1955. Ressalta ainda que a utilização do jornal nas escolas está, na maioria das vezes, vinculada às empresas jornalísticas que visam a atrair cada vez mais leitores de jornal. Um exemplo é o jornal Zero Hora, de Porto Alegre - RS, considerado uma pioneiro neste ramo no Brasil. O jornal mantém desde 1980, programas para professores e alunos, sendo esta atividade desenvolvida depois por outras empresas jornalísticas.

A utilização do jornal impresso como recurso escolar estimula a comunicação, a troca de experiências, o respeito a diferentes pontos de vista, uma vez que apresenta diferentes formas e mensagens (manchetes, fotografias, charges, pesquisas, etc.).

O trabalho com o jornal na sala de aula, além de possibilitar o enriquecimento e atualização do conteúdo escolar, contribui para que as informações veiculadas se apresentem como um canal aberto entre a sala de aula e a dinâmica da realidade social, levando o pensamento não à conformação, mas à crítica e à participação. (TREVISANI E OUTROS, 1998, p.19)

Desta forma, o uso do jornal como recurso didático nem sempre é explorado de forma pedagógica ou, quando utilizado, visa apenas a ser mais um material para trabalhos artísticos, Arte entendida não como espaço de criação, mas apenas de entretenimento.

\section{CONSIDERAÇÕES FINAIS}

É importante desenvolver estudos acerca da utilização da mídia como recurso nos espaços formais de ensino, sobretudo diante das Questões Ambientais, para tanto, é preciso romper com as ideias simplistas. Este trabalho, recorte de um trabalho de pesquisa mais amplo, ensaiou a discussão acerca da mídia como espaço de criação. Para tanto, pudemos perceber que a teoria de Vygotsky pode ser um aporte teórico relevante, haja vista apresentar um conceito de Sujeito.

\section{REFERÊNCIAS}

BOURDIEU, P. Sobre a televisão. Rio de Janeiro: Zahar Editores, 1997. 
CAMPOS, C. C. G. de, SOUZA, S. J. Mídia, cultura do consumo e constituição da subjetividade na infância. Psicologia, Ciência e Profissão, 2003,23 (1), 12-21.

CERTEAU, M. A invenção do Cotidiano: 1.artes de fazer. 7. ed. Petrópolis: Vozes, 1994.

DIAS, G. F. Educação Ambiental: princípios e práticas. 8. ed. São Paulo: Gaia, 2003. FREIRE, P. 'Criando Métodos de Pesquisa Alternativa: aprendendo a fazê-la melhor através da ação'. BRANDÃO, Carlos (ORG.). Pesquisa Participante. $6^{a}$ edição. São Paulo: Editora Brasiliense, 1986.

GUIMARÃES, M. e VASCOCELLOS, M.M.N. Relações entre educação ambiental e educação em ciências na complementaridade dos espaços formais e não formais de educação. Educar, Curitiba, n. 27, p. 147-162, 2006. Editora UFPR.

OLIVEIRA, L., CRIBB, S.; RAMOS, G., ROCHA, P., MENDONÇA, L. A divulgação científica de temas de saúde: análise de um impresso. Ciência em Tela, v.3, n.1, 2010.

OLIVEIRA, L., CRIBB, S., RAMOS, G., SERRA, S., PICANÇO, R. Mídia e divulgação científica: a interface entre ensino de ciências, comunicação social e psicologia. Anais do XIV Encontro Nacional da ABRAPSO. Rio de Janeiro: ABRAPSO, 2007.

OLIVEIRA, M.K. Sobre as diferenças individuais e as diferenças culturais: o lugar da abordagem histórico-cultural. AQUINO, J.G. (org.). Erro e Fracasso na Escola: alternativas teóricas e práticas. $5^{\text {a }}$ edição. São Paulo: Summus, 1997.

OLIVEIRA, M.K. Vygotsky: alguns equívocos na interpretação de seu pensamento. Cadernos de Pesquisa. São Paulo: 1996, n. 81.

REGO, T. C. Vygotsky: uma perspectiva histórico-cultural da Educação. $10^{\mathrm{a}}$ edição. Petrópolis: Vozes, 2000.

REIGOTA, M. Meio Ambiente e Representação Social. São Paulo: Cortez, 1995.

TREVISANI, M. L. L., MOREIRA, A. L. O. R., GALUCH, M. T. B., SFORNI, M. S. F. Jornal na escola: da informação à opinião esclarecida. Comunicação e Educação, São Paulo, (12): 17 a 23, maio/ago, 1998.

VYGOTSKY, L. Pensamento e Linguagem. 10ª edição. Petrópolis: Vozes, 2001.

VYGOTSKY, L. A Formação Social da Mente. São Paulo: Martins Fontes, 1994.

VYGOTSKY, L. Psicologia del arte. Barcelona: Barral Editores, 1972. 